Xiangming Guo $\cdot$ Shiqiang Li $\cdot$ Xiaoyun Jia

Xueshan Xiao · Panfeng Wang $\cdot$ Qingjiong Zhang

\title{
Linkage analysis of two families with X-linked recessive congenital motor nystagmus
}

Received: 15 August 2005 / Accepted: 9 September 2005 / Published online: 21 October 2005

(C) The Japan Society of Human Genetics and Springer-Verlag 2005

\begin{abstract}
X-linked recessive congenital motor nystagmus was identified in two Chinese families living in the Guangdong province of China. Nystagmus was noticed in early childhood. Only males in the families were affected and all obligate carriers did not have nystagmus. Linkage study was performed using microsatellite markers at about $10 \mathrm{cM}$ intervals on the $\mathrm{X}$ chromosome. The nystagmus in these two families is linked to markers in the region of chromosome Xq23-q27, including DXS1001, DXS8009, and DXS1047. DXS1047 gave the highest lod score of 3.53 at $\theta=0$.
\end{abstract}

Keywords Congenital motor nystagmus .

$\mathrm{X}$-linked recessive $\cdot$ Linkage $\cdot$ Locus $\cdot \mathrm{NYS} 1$

\section{Introduction}

Congenital nystagmus (CN) is an ocular condition characterized by bilateral involuntary ocular oscillation. $\mathrm{CN}$ is commonly observed in ocular diseases such as albinism, Leber congenital amaurosis, aniridia, cone or cone-rod dystrophy, macular coloboma, optic nerve dysplasia, etc. In rare cases, $\mathrm{CN}$ may occur without any other known ocular or systemic disease, and is referred to as idiopathic $\mathrm{CN}$ or congenital motor nystagmus (CMN) (Cabot et al. 1999; Kerrison et al. 1999). Patients with $\mathrm{CMN}$ have normal or mild-to-moderately reduced visual acuity. Their optic media, fundus appearance, and

X. Guo $\cdot \mathrm{S}$. Li $\cdot$ X. Jia $\cdot$ X. Xiao $\cdot$ P. Wang $\cdot$ Q. Zhang

Key Laboratory of Ophthalmology of the Ministry of Education,

Sun Yat-sen University, Guangzhou,

People's Republic of China

X. Guo $\cdot$ S. Li $\cdot$ X. Jia $\cdot$ X. Xiao $\cdot$ P. Wang $\cdot$ Q. Zhang $(\triangle)$ Zhongshan Ophthalmic Center, Sun Yat-sen University,

54 Xianlie Road, 510060 Guangzhou,

People's Republic of China

E-mail: qingjiongzhang@yahoo.com

Tel.: + 86-20-87330400

Fax: $+86-20-87333271$ cone-rod function are rather normal. These lead to a presumption that the primary defect of $\mathrm{CMN}$ is in the central nervous system, where ocular motor function is controlled.

CMN has been described as being transmitted as an autosomal dominant (OMIM 164100, NYS2; OMIM 608345, NYS3; OMIM 193003), autosomal recessive (OMIM 257400), and X-linked dominant or recessive (OMIM 310700) trait. No gene has been identified as being responsible for $\mathrm{CMN}$, although linkage studies have suggested several loci on chromosome Xp11.4 $\mathrm{p} 11.3$, Xq26-q27, and 6p12, for X-linked dominant (Cabot et al. 1999; Kerrison et al. 1999, 2001; Zhang et al. 2005) and autosomal dominant (Kerrison et al. 1996) CMN. The genetic locus for X-linked recessive $\mathrm{CMN}$ has not been reported. Here, we describe two families with $\mathrm{X}$-linked recessive $\mathrm{CMN}$ and map the disease to Xq23-q27, between DXS8055 and DXS1205.

\section{Materials and methods}

Families and clinical data

Two families living in Guangdong province with Xlinked recessive $\mathrm{CMN}$, including nine affected and ten unaffected individuals, participated in the linkage study. Informed consent conforming to the tenets of the Declaration of Helsinki and following the Guidance of Sample Collection of Human Genetic Diseases (863Plan) by the Ministry of Public Health of China was obtained from the participating individuals prior to the study. Ophthalmological examination (by X.G. and Q.Z.) included visual acuity, color vision, slit-lamp, and funduscopic examinations. A subject was considered to have CMN if the following criteria were met: (1) CN noted before 1 year old; (2) clear optic medium with normal appearance of fundus; (3) normal color vision and no night blindness; and (4) exclusion of other known ocular or systemic diseases. Electroretinogram $(E R G)$ responses were recorded in selected patients 

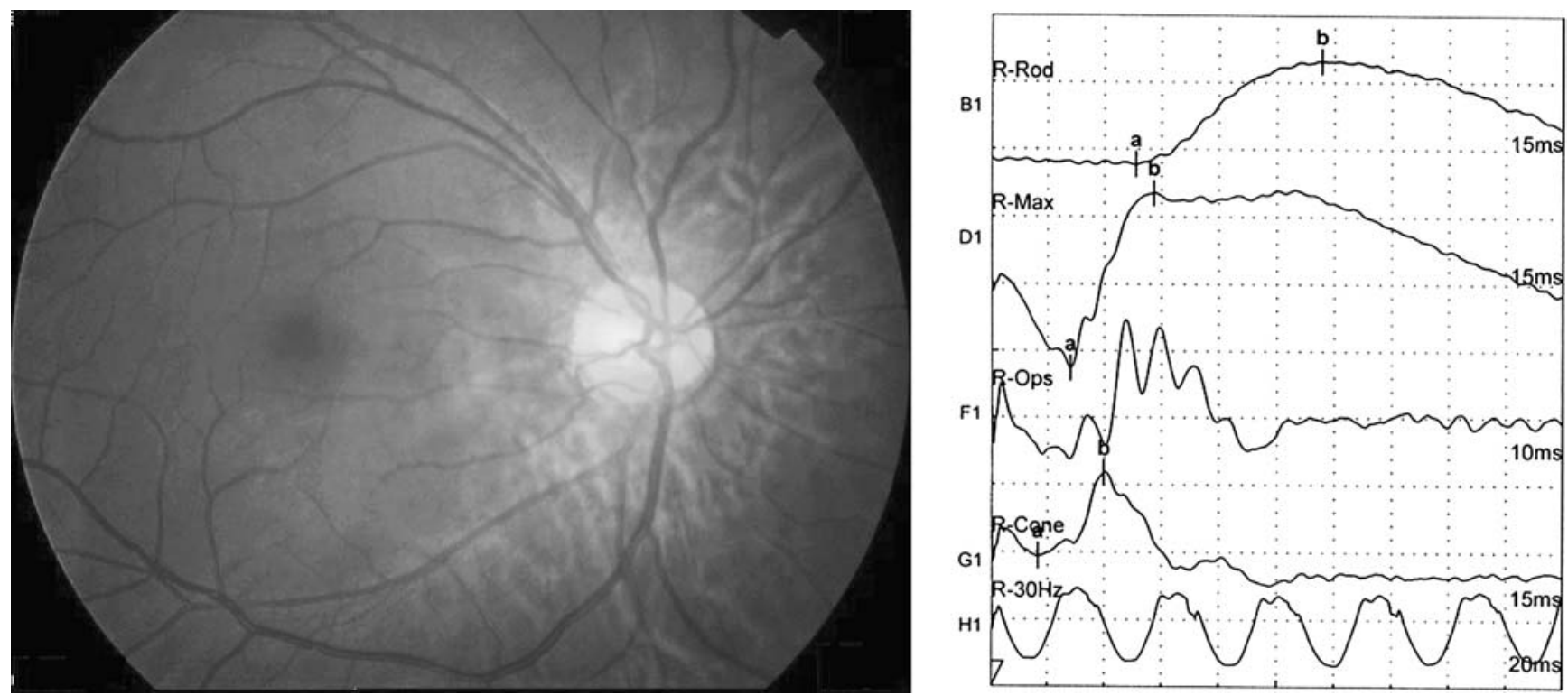

Fig. 1 Fundus photograph and electroretinogram (ERG) recording. An example of the normal fundus appearance and normal cone-rod response on ERG recording of the individual III6 in family B is shown

consistent with International Society for Clinical Electrophysiology of Vision standards (ISCEV 1989). Genomic DNA was prepared from venous blood.

Genotyping and linkage analysis

Genotyping for all participating family members was performed using 5 'fluorescently labeled microsatellite markers. An X chromosome-wide scan was carried out using 28 panels of the ABI PRISM linkage Mapping Set Version 2, which included 18 markers spaced at intervals of about $10 \mathrm{cM}$. Polymerase chain reaction (PCR) was conducted at $94^{\circ} \mathrm{C}$ for $8 \mathrm{~min}$, followed by 10 cycles of amplification at $94^{\circ} \mathrm{C}$ for $15 \mathrm{~s}, 55^{\circ} \mathrm{C}$ for $15 \mathrm{~s}$, and $72^{\circ} \mathrm{C}$ for $30 \mathrm{~s}$; then 20 cycles at $89^{\circ} \mathrm{C}$ for $15 \mathrm{~s}, 55^{\circ} \mathrm{C}$ for $15 \mathrm{~s}$, $72^{\circ} \mathrm{C}$ for $30 \mathrm{~s}$; finally at $72^{\circ} \mathrm{C}$ for $10 \mathrm{~min}$. After mixing with GENESCAN 400HD [ROX] standard (ABI) and

Table 1 Two-point linkage results between microsatellite markers of the $\mathrm{X}$ chromosome and congenital motor nystagmus (CMN) in the Chinese families

\begin{tabular}{|c|c|c|c|c|c|c|c|c|c|c|c|}
\hline \multirow[t]{2}{*}{ Markers $^{\mathrm{a}}$} & \multicolumn{2}{|c|}{ Position } & \multicolumn{7}{|c|}{ Lod score at $\theta=$} & \multirow[t]{2}{*}{$Z_{\max }$} & \multirow[t]{2}{*}{$\theta_{\max }$} \\
\hline & $\mathrm{cM}$ & $\mathrm{Mb}$ & 0 & 0.01 & 0.05 & 0.1 & 0.2 & 0.3 & 0.4 & & \\
\hline DXS1060 & 10.10 & 4.87 & $-\infty$ & -6.71 & -3.33 & -1.96 & -0.76 & -0.23 & -0.01 & 0.02 & 0.46 \\
\hline DXS8051 & 15.70 & 8.91 & $-\infty$ & -6.50 & -3.14 & -1.81 & -0.67 & -0.19 & 0.00 & 0.02 & 0.4 \\
\hline DXS987 & 25.50 & 14.07 & $-\infty$ & -3.91 & -1.90 & -1.11 & -0.44 & -0.15 & -0.03 & 0.00 & 0.48 \\
\hline DXS1226 & 36.80 & $?$ & $-\infty$ & -0.81 & 0.40 & 0.75 & 0.84 & 0.63 & 0.31 & 0.85 & 0.17 \\
\hline DXS1214 & 46.20 & 30.62 & $-\infty$ & -0.73 & 0.49 & 0.87 & 0.98 & 0.80 & 0.47 & 0.99 & 0.17 \\
\hline DXS1068 & 56.20 & 37.94 & $-\infty$ & -3.10 & -1.14 & -0.41 & 0.12 & 0.26 & 0.20 & 0.26 & 0.31 \\
\hline DXS993 & 66.10 & 40.90 & $-\infty$ & -5.61 & -2.88 & -1.77 & -0.78 & -0.30 & -0.07 & 0.00 & 0.5 \\
\hline DXS991 & 86.90 & 55.40 & $-\infty$ & -5.18 & -2.47 & -1.38 & -0.46 & -0.08 & 0.04 & 0.05 & 0.41 \\
\hline DXS986 & 95.90 & 79.19 & $-\infty$ & -1.32 & -0.05 & 0.39 & 0.63 & 0.58 & 0.36 & 0.64 & 0.22 \\
\hline DXS990 & 104.90 & 92.81 & $-\infty$ & -4.37 & -2.30 & -1.45 & -0.67 & -0.30 & -0.10 & 0.02 & 0.5 \\
\hline DXS1106 & 115.10 & 102.54 & $-\infty$ & -3.37 & -1.41 & -0.68 & -0.13 & 0.04 & 0.06 & 0.06 & 0.37 \\
\hline DXS1210 & 119.20 & 108.40 & $-\infty$ & -0.56 & 0.06 & 0.25 & 0.33 & 0.27 & 0.15 & 0.33 & 0.19 \\
\hline DXS8055 & 126.80 & 114.48 & $-\infty$ & 0.88 & 1.39 & 1.44 & 1.22 & 0.83 & 0.39 & 1.45 & 0.09 \\
\hline DXS1001 & 139.40 & 119.62 & 2.33 & 2.29 & 2.13 & 1.93 & 1.50 & 1.04 & 0.55 & 2.33 & 0.00 \\
\hline DXS8009 & 148.40 & 125.90 & 2.37 & 2.32 & 2.15 & 1.92 & 1.44 & 0.92 & 0.38 & 2.37 & 0.00 \\
\hline DXS1047 & 150.30 & 128.80 & 3.53 & 3.48 & 3.25 & 2.95 & 2.32 & 1.63 & 0.86 & 3.53 & 0.00 \\
\hline DXS1205 & 163.70 & 139.99 & $-\infty$ & -0.26 & 0.34 & 0.51 & 0.53 & 0.42 & 0.23 & 0.55 & 0.16 \\
\hline DXS1227 & 164.70 & 140.53 & $-\infty$ & -2.26 & -0.94 & -0.45 & -0.07 & 0.05 & 0.06 & 0.06 & 0.3 \\
\hline DXS8043 & 176.70 & 143.73 & $-\infty$ & -4.81 & -2.16 & -1.16 & -0.37 & -0.11 & -0.04 & 0.28 & 0.7 \\
\hline DXS8091 & 186.30 & 147.31 & $-\infty$ & -6.37 & -3.58 & -2.40 & -1.27 & -0.67 & -0.27 & 0.32 & 0.7 \\
\hline DXS1073 & 196.50 & 153.39 & $-\infty$ & -7.60 & -4.16 & -2.73 & -1.38 & -0.67 & -0.25 & 0.11 & 0.6 \\
\hline
\end{tabular}

${ }^{a}$ DXS8081 and DXS8064 between DXS8055 and DXS1001, DXS8074 and DXS1062 between DXS1047 and DXS1205, as well as DXS8057 between DXS1001 and DXS8009, were genotyped but were uninformative in these families 
deionized formamide, PCR products were denatured at $96^{\circ} \mathrm{C}$ for $5 \mathrm{~min}$ and then immediately placed on ice for 5 min. The amplicons were separated on an ABI3100 DNA sequencer. Genotyping data were analyzed using the Gene Mapper version 3.5 software package from ABI. Two-point linkage analysis was performed by using the MLINK program of the FASTLINK implementation of the LINKAGE program package (Lathrop and Lalouel 1984; Schaffer et al. 1994). Only one set of genotyping data from the homozygote twins (individuals V1 and V2 in family B) was used to calculate lod scores. $\mathrm{CMN}$ in the two families was analyzed as an X-linked recessive trait with full penetrance and a disease-gene allele frequency of 0.0001 . Additional markers were selected around the candidate region according to the National Center for Biotechnology Information map.
Haplotypes were generated using the program Cyrillic 2.1 , and confirmed by inspection.

\section{Results}

In the two families with $\mathrm{X}$-linked recessive $\mathrm{CMN}$, the disease was transmitted from female carrier to affected son. All affected individuals were male and all obligate carriers had no sign of nystagmus. All affected individuals were noticed to have nystagmus in early childhood. Of the six affected individuals, visual acuity was over 0.8 in three cases and between 0.3 and 0.5 in three cases. Complaints of night blindness or photophobia were not recorded in any affected individual in the two families. In a recent examination, the optic medium and fundus of
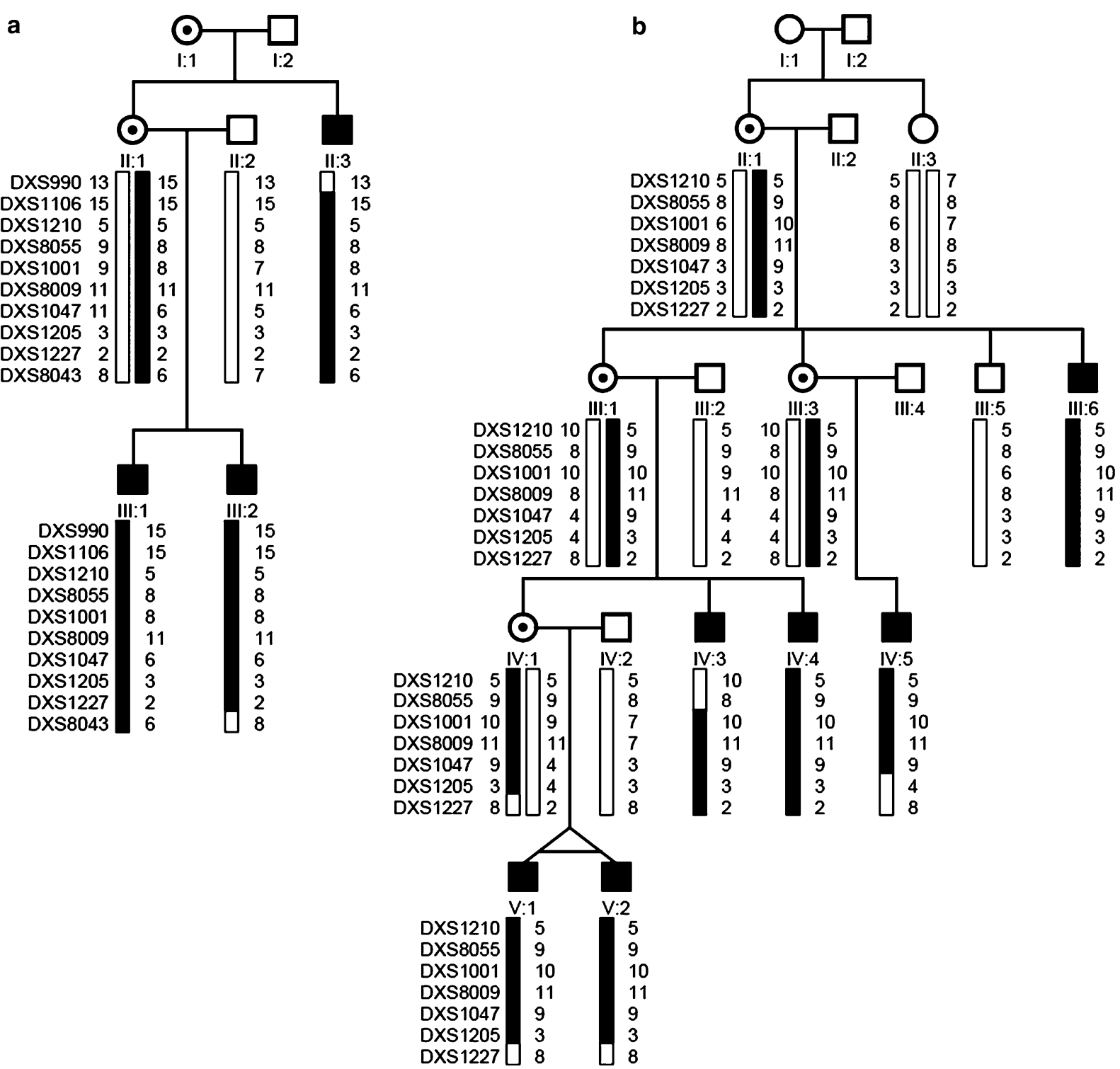

Fig. 2 Pedigree and haplotype of the two families with congenital motor nystagmus (CMN). Black bars Disease allele, open bars normal alleles. Black squares Individuals affected with $\mathrm{CMN}$, circles with black dots obligate carriers 
Fig. 3 Diagram of the $X$ chromosome showing the critical region for X-linked CMN. $A, B, C$ Critical regions for X-linked dominant CMN reported by Kerrison et al. (1999, 2001) and Zhang et al. (2005), respectively; $D$ linked region for $\mathrm{X}$-linked recessive $\mathrm{CMN}$ in this study

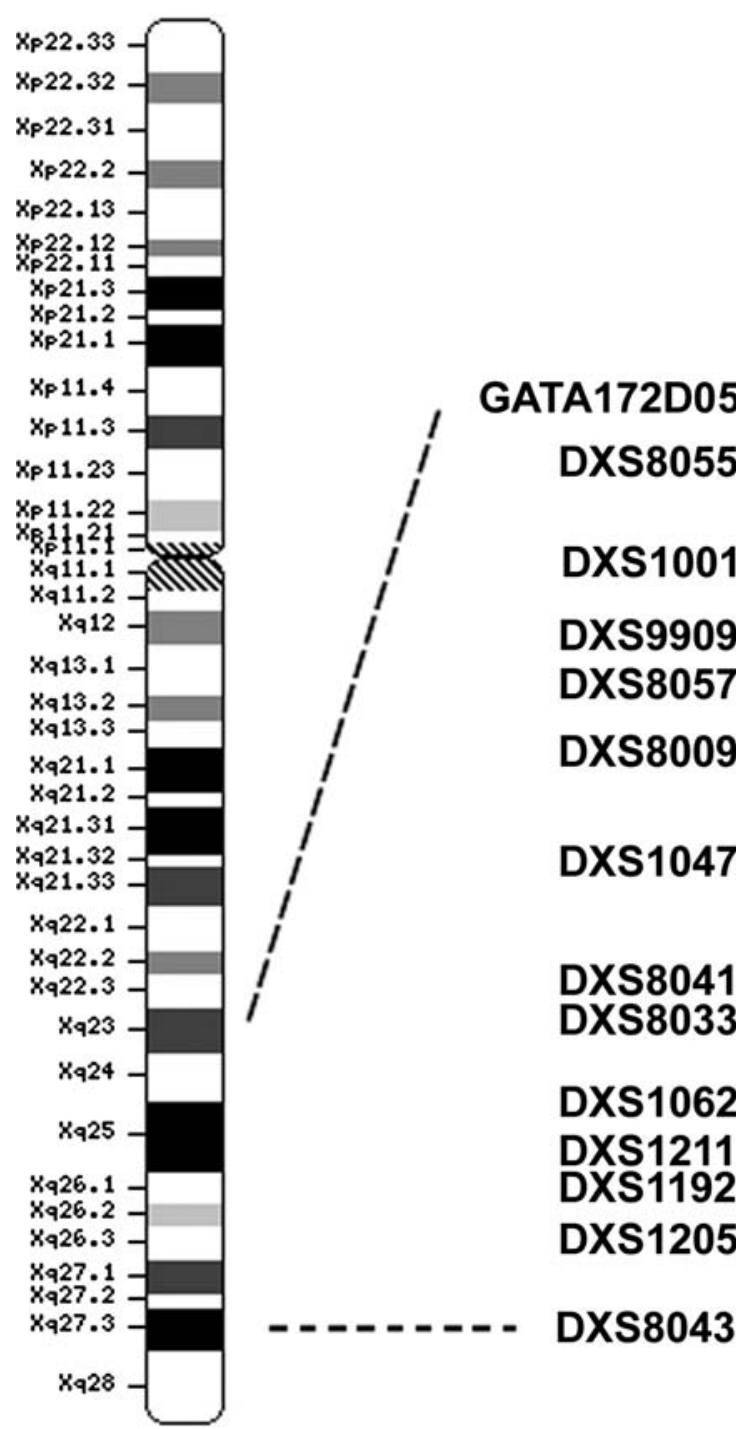

all affected individuals were normal (Fig. 1). Normal color vision was recorded in four affected individuals (individuals III6, IV3, IV4, and IV5), and the other two were too young to read Ishihara plates for color vision evaluation. ERG recorded in individual III6 showed normal cone and rod response (Fig. 1).

Upon an initial $\mathrm{X}$ chromosome scan, two-point linkage analysis excluded all $\mathrm{X}$ chromosome markers with lod scores of minus infinity except DXS1001 and DXS1047, which gave lod scores greater than 2. Fine mapping and haplotype analysis confirmed the locus on Xq23-q27 (Table 1, Fig. 2). Three microsatellite markers, DXS1001, DXS8009, and DXS1047, generated positive lod scores, with the highest lod score of 3.53 for $D X S 1047$ at $\theta=0$.

Haplotypes in this region of both families supported the linkage results (Fig. 2). Recombination at DXS8055 for individual IV3 set the centromeric boundary, and recombination at $D X S 1205$ in individual IV5 with further recombination at DXS1227 in individual IV1 (confirmed in individuals V1 and V2) set the telomeric boundary for the linked region. Therefore, the disease gene should be located between DXS8055 and DXS1205.

\section{Discussion}

In this study, $\mathrm{X}$-linked recessive $\mathrm{CMN}$ in two Chinese families was mapped to a locus on chromosome Xq23q27 between $D X S 8055$ and $D X S 1205$. Exclusion of other regions in the $\mathrm{X}$ chromosome by lod scores of minus infinity, lod scores greater than 2 for three markers inside the linked region (Terwilliger and Ott 1994), and haplotype observation, all support the conclusion that this locus is linked to $\mathrm{X}$-linked recessive CMN.

$\mathrm{X}$-linked dominant $\mathrm{CMN}$ with incomplete penetrance among female carriers has been mapped to two regions: Xp11.4-p11.3 (Cabot et al. 1999) and Xq26-q27 (Kerrison et al. 1999, 2001; Zhang et al. 2005). The X-linked recessive $\mathrm{CMN}$ in the two Chinese families examined 
here mapped to Xq23-q27, which harbors the X-linked dominant CMN locus (Fig. 3). The present result provides evidence that $\mathrm{X}$-linked recessive $\mathrm{CMN}$ and $\mathrm{X}$ linked dominant CMN may be caused by the same gene with different mutations. Different mutations in the same gene causing a similar phenotype but with a different pattern of inheritance have been identified in several genes related to ocular diseases, e.g., $R P 1$ (Khaliq et al. 2005; Riazuddin et al. 2005; Sullivan et al. 1999), RHO (Dryja et al. 1990; Rosenfeld et al. 1992), LRP5 (Jiao et al. 2004; Toomes et al. 2004), etc. On the other hand, linkage to the same region does not rule out the possibility that the disease may result from mutation of different genes (Toomes et al. 2004). These possibilities can be easily resolved upon cloning of the causative gene.

Several candidate genes, including $C D R 1, S O X 3$, SLC25A14, SLC9A6, and FGF13, have been screened in patients with $\mathrm{X}$-linked dominant $\mathrm{CMN}$ but no causative mutations were detected (Kerrison et al. 1999, 2001; Zhang et al. 2005). Other potential candidate genes inside the linked interval include, but are not limited to, GRIA3, MBNL3, and FHL1.

Three other X-linked disorders, including NettleshipFalls ocular albinism (OMIM 300500), CSNB1 (OMIM 310500), and blue-cone monochromacy (OMIM 303700), have nystagmus in addition to their specific defects. Linkage to loci for these three disorders in the two Chinese families studied here is excluded by linkage analysis, and the clinical manifestation is different.

Acknowledgements The authors thank all patients and family members for their participation. This study was supported in part by the National 863 Plan of China (04AA104092 to X.G.; Z19-0104-02 to Q.Z.), Guangdong Natural Science Foundation (04009335 to X.G.; 010765 to Q.Z.), and Returnee Foundation from Sun Yatsen University (3030901010022 to Q.Z.) and Zhongshan Ophthalmic Center (3031002006 to Q.Z.).

\section{References}

Cabot A, Rozet JM, Gerber S, Perrault I, Ducroq D, Smahi A, Souied E, Munnich A, Kaplan J (1999) A gene for X-linked idiopathic congenital nystagmus (NYS1) maps to chromosome Xp11.4-p11.3. Am J Hum Genet 64:1141-1146

Dryja TP, McGee TL, Reichel E, Hahn LB, Cowley GS, Yandell DW, Sandberg MA, Berson EL (1990) A point mutation of the rhodopsin gene in one form of retinitis pigmentosa. Nature 343:364-366
ISCEV (1989) Standard for clinical electroretinography. International Society for Clinical Electrophysiology of Vision. International Standardization Committee. Arch Ophthalmol 107:816-819

Jiao X, Ventruto V, Trese MT, Shastry BS, Hejtmancik JF (2004) Autosomal recessive familial exudative vitreoretinopathy is associated with mutations in LRP5. Am J Hum Genet 75:878884

Kerrison JB, Arnould VJ, Barmada MM, Koenekoop RK, Schmeckpeper BJ, Maumenee IH (1996) A gene for autosomal dominant congenital nystagmus localizes to $6 \mathrm{p} 12$. Genomics 33:523-526

Kerrison JB, Vagefi MR, Barmada MM, Maumenee IH (1999) Congenital motor nystagmus linked to Xq26-q27. Am J Hum Genet 64:600-607

Kerrison JB, Giorda R, Lenart TD, Drack AV, Maumenee IH (2001) Clinical and genetic analysis of a family with Xlinked congenital nystagmus (NYS1). Ophthalmic Genet 22:241-248

Khaliq S, Abid A, Ismail M, Hameed A, Mohyuddin A, Lall P, Aziz A, Anwar K, Mehdi SQ (2005) Novel association of RP1 gene mutations with autosomal recessive retinitis pigmentosa. J Med Genet 42:436-438

Lathrop GM, Lalouel JM (1984) Easy calculations of lod scores and genetic risks on small computers. Am J Hum Genet 36:460465

Riazuddin SA, Zulfiqar F, Zhang Q, Sergeev YV, Qazi ZA, Husnain T, Caruso R, Riazuddin S, Sieving PA, Hejtmancik JF (2005) Autosomal recessive retinitis pigmentosa is associated with mutations in rpl in three consanguineous Pakistani families. Invest Ophthalmol Vis Sci 46:2264-2270

Rosenfeld PJ, Cowley GS, McGee TL, Sandberg MA, Berson EL, Dryja TP (1992) A null mutation in the rhodopsin gene causes rod photoreceptor dysfunction and autosomal recessive retinitis pigmentosa. Nat Genet 1:209-213

Schaffer AA, Gupta SK, Shriram K, Cottingham RW Jr (1994) Avoiding recomputation in linkage analysis. Hum Hered $44: 225-237$

Sullivan LS, Heckenlively JR, Bowne SJ, Zuo J, Hide WA, Gal A, Denton M, Inglehearn CF, Blanton SH, Daiger SP (1999) Mutations in a novel retina-specific gene cause autosomal dominant retinitis pigmentosa. Nat Genet 22:255-259

Terwilliger JD, Ott J (1994) Handbook of human genetic linkage. Johns Hopkins University Press, Baltimore

Toomes C, Bottomley HM, Jackson RM, Towns KV, Scott S, Mackey DA, Craig JE, Jiang L, Yang Z, Trembath R, Woodruff G, Gregory-Evans CY, Gregory-Evans K, Parker MJ, Black GC, Downey LM, Zhang K, Inglehearn CF (2004) Mutations in LRP5 or FZD4 underlie the common familial exudative vitreoretinopathy locus on chromosome 11q. Am J Hum Genet 74:721-730

Zhang B, Xia K, Ding M, Liang D, Liu Z, Pan Q, Hu Z, Wu LQ, Cai F, Xia J (2005) Confirmation and refinement of a genetic locus of congenital motor nystagmus in Xq26.3-q27.1 in a Chinese family. Hum Genet 116:128-131 